\title{
A successful application of adult polymyxin B-immobilized fiber column hemoperfusion to a neonate with septic shock
}

\author{
Young A Kim', Hyungtae Kim², Yu-Mi Kim³ , Su Eun Park' \\ ${ }^{1}$ Department of Pediatrics, Pusan National University Children's Hospital, Yangsan; ${ }^{2}$ Department of Thoracic and Cardiovascular Surgery and ${ }^{3}$ Artificial \\ Kidney Unit, Pusan National University Yangsan Hospital, Yangsan, Korea
}

Direct hemoperfusion therapy with a polymyxin B-immobilized fiber column (PMX-HP) has been introduced as a therapeutic option for gram negative bacterial septic shock in adults. However, its use in neonates and children has not yet been established. We successfully performed hemoperfusion therapy using an adult polymyxin B-immobilized fiber column in a neonate with carbapenem resistant Acinetobacter baumannii septic shock. The application was technically feasible because the neonate was on extracorporeal membrane oxygenation (ECMO). Although it did not rescue the patient, there was significant short-lasting improvement in pulmonary oxygenation and hemodynamics, leading to wean the patient from ECMO. PMX-HP could be used as an adjunctive treatment for selected neonatal and pediatric patients with gram negative bacterial septic shock.

Key Words: extracorporeal membrane oxygenation; hemoperfusion; neonate; polymyxin B

Direct hemoperfusion therapy with a polymyxin B-immobilized fiber column (PMX-HP) has been introduced as a therapeutic option for gram negative bacterial septic shock in adults [1-3], and its main mechanism of action is the selective absorption of circulating endotoxins without toxicity [4]. Although the characteristics and responses of neonatal sepsis differ from those of adults [5], PMX-HP reduced levels of immune mediators such as interleukin-6, highly mobile group-1 box protein, or interferon gamma in neonatal sepsis model [6], as in adult studies [3,7]. However, polymyxin Bimmobilized fiber cartridges for children as well as neonates are not available in most countries except Japan, and a few reports on its use in neonates have been found in the literature [8,9]. Here, we report a case of the successful application of adult polymyxin B-immobilized fiber column hemoperfusion to a neonate with carbapenem resistant Acinetobacter baumannii (CRAB) septic shock, who was on extracorporeal membrane oxygenation (ECMO) support.

\section{CASE REPORT}

A female neonate was born with a gestational age of $38^{+0}$ weeks and a birth weight of $3.0 \mathrm{~kg}$. The next day, she was transported to the neonatal intensive care unit in Pusan National

\section{Case Report}

Received: October 15, 2017

Revised: February 2, 2018

Accepted: February 11, 2018

Corresponding author

Young A Kim

Department of Pediatrics, Pusan

National University Children's

Hospital, 20 Geumo-ro, Mulgeum-

eup, Yangsan 50612, Korea

Tel: +82-55-360-3516

Fax: +82-55-360-2181

E-mail:youngflo@hanmail.net

Copyright @ 2019 The Korean Society of Critical Care Medicine

This is an Open Access article distributed under the terms of Creative Attributions Non-Commercial License (http:// creativecommons.org/li-censes/by-nc/4.0] which permits unrestricted noncommercial use, distribution, and reproduction in any medium, provided the original work is properly cited. 
University Children's Hospital due to respiratory distress and was diagnosed with right congenital diaphragmatic hernia. The patient underwent a diaphragm repair operation, and was supported by conventional mechanical ventilator.

On the 7th day of life, she suddenly showed hypotension, metabolic and respiratory acidosis with an oxygenation index of 27.4 , an increased total leukocyte count of 41,520 cells/ $\mu \mathrm{l}$ (segmented neutrophil, 63\%) and elevated C-reactive protein level of $13.9 \mathrm{mg} / \mathrm{dl}$. Chest radiograph showed no pneumonic infiltration. Under suspicion of septic shock, intravenous vancomycin and meropenem were initiated as empirical antibiotics, and intravenous immunoglobulin ( $2 \mathrm{~g} / \mathrm{kg})$ and hydrocortisone ( $1 \mathrm{mg} / \mathrm{kg} /$ dose) were also used. Despite the medications and the application of high-frequency oscillation ventilation with inhaled nitric oxide, the patient's oxygenation index rapidly increased to 96 , and the pediatric risk of mortality III score was 29 [10]. The inotropic score was 140, which was calculated as followed formula: dopamine dose $(\mu \mathrm{g} / \mathrm{kg} / \mathrm{min})$ +dobutamine dose $(\mu \mathrm{g} / \mathrm{kg} / \mathrm{min})+100 \times$ epinephrine dose $(\mu \mathrm{g} /$ $\mathrm{kg} / \mathrm{min}$ ) [11]. The patient was transferred to the pediatric intensive care unit for ECMO support.

Through median sternotomy, an 8-F inflow cannula was inserted into the main pulmonary artery and 16-F drainage cannula was placed in the right atrium. Veno-venous ECMO support was applied and maintained at $45 \%-60 \%$ of the flow rate of patient's cardiac index $\left(500 \mathrm{ml} / \mathrm{min} / \mathrm{m}^{2}\right)$. Blood culture study reported the growth of Acinetobacter baumannii, which was extensively drug-resistant involving carbapenem. According to the drug sensitivity, intravenous high-dose ampicillin/sulbactam (400 mg ampicillin/kg/day), intravenous colistin ( $5 \mathrm{mg} / \mathrm{kg} /$ day), and oral minocycline (4 mg/kg/day) were administered.

On the 12th day of life, we tried to wean the patient from the ECMO support because pulmonary hypertension on echocardiography and hemodynamics had improved (inotropic score 25), and pulmonary oxygenation was tolerable (Figure 1). However, the patient was not ready in the weaning trial.

On the 14th day of life, since the $\mathrm{PaO}_{2} / \mathrm{FiO}_{2}$ ratio had gradually decreased to 76 and urination was decreased $(0.9 \mathrm{ml} / \mathrm{kg} / \mathrm{hr})$, inhaled nitric oxide reapplied and continuous renal replacement therapy (CRRT) was also applied to the ECMO circuit. The needs for vasoactive drugs increased (inotropic score 55). The decision to apply PMX-HP was made, and written informed consent was obtained from the patient's parents.

An adult polymyxin B-immobilized fiber column (Toraymyxin 20-R; Toray Medical Co., Tokyo, Japan) was deployed to a different renal replacement therapy machine (Figure 2A). The volume of the circuit (108 ml) with the fiber column (135 $\pm 5 \mathrm{ml}$ ) was $247 \mathrm{ml}$. The circuit was primed with packed red blood cells (RBCs), normal saline, and sodium bicarbonate

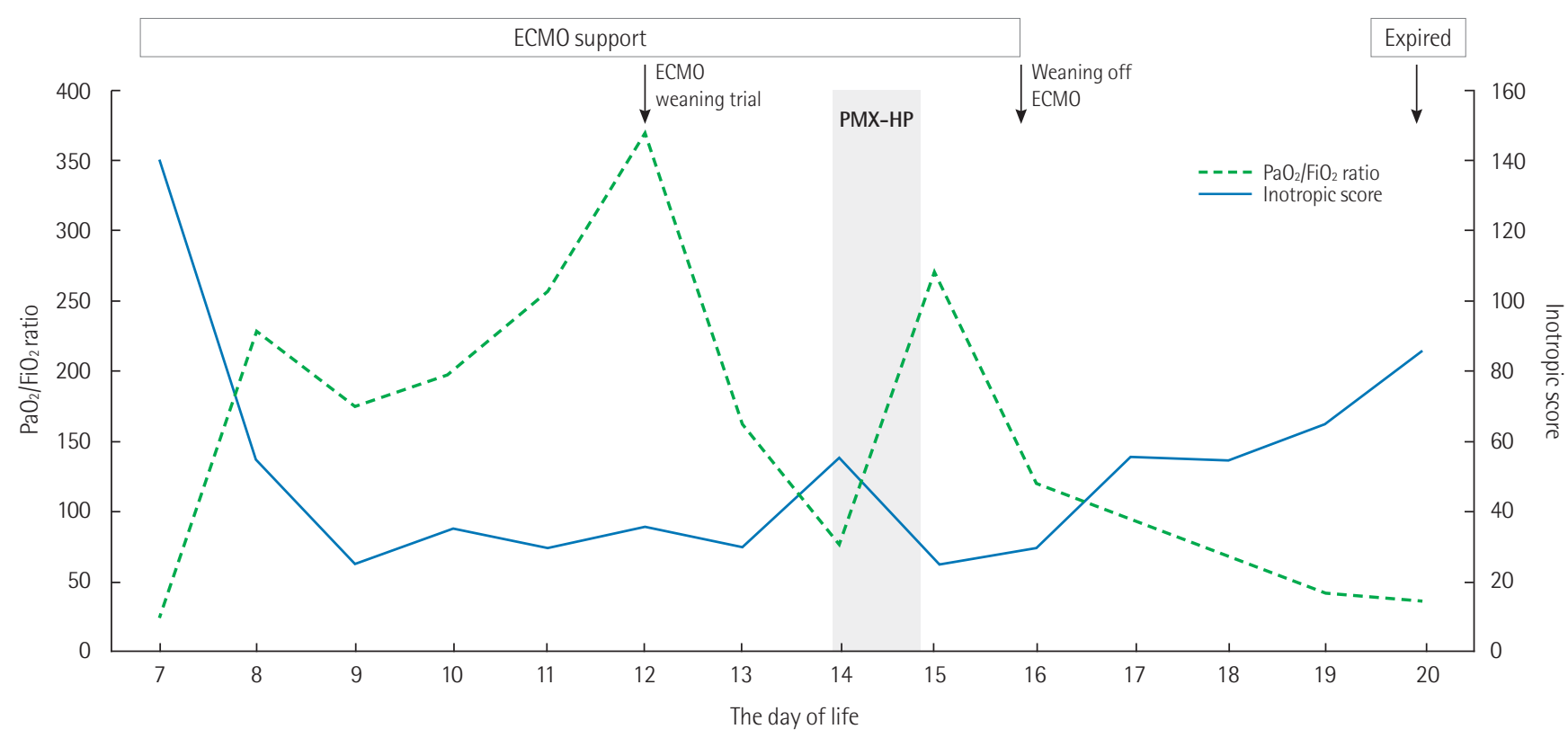

Figure 1. Clinical course and serial changes of $\mathrm{PaO}_{2} / \mathrm{FiO}_{2}$ ratio and inotropic score. ECMO was applied to a 7-day-old neonate with septic shock. After the application of $\mathrm{PMX}-\mathrm{HP}, \mathrm{PaO}_{2} / \mathrm{FiO}_{2}$ ratio was improved and inotropic score decreased, and the ECMO was discontinued. However, the patient's condition deteriorated and the patient died on the 20th day of life. ECM0: extracorporeal membrane oxygenation; PMX-HP: hemoperfusion therapy with a polymyxin B-immobilized fiber column. 

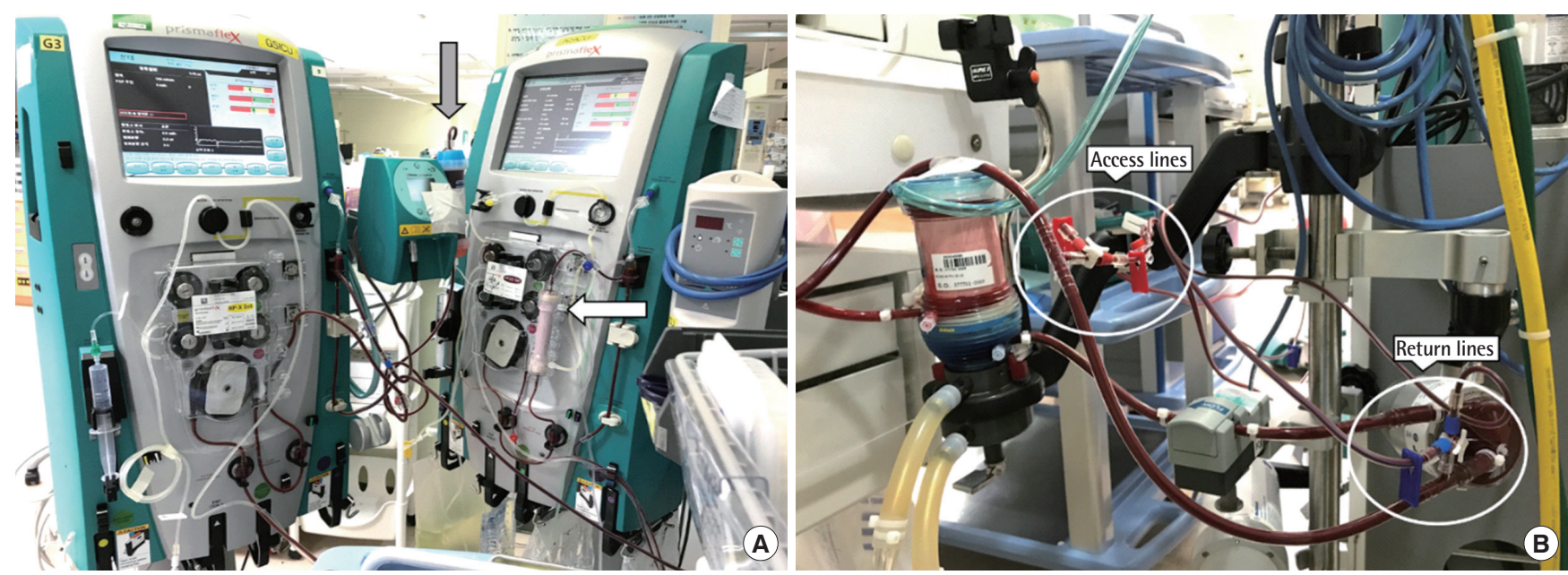

Figure 2. Pictures of devices. (A) An adult polymyxin B-immobilized fiber column (gray arrow) with a circuit and a hemofiltration set (white arrow) were placed on each device. (B) The access lines of the polymyxin B direct hemoperfusion device and continuous renal replacement therapy were simultaneously connected to the proximal drainage line of the extracorporeal membrane oxygenation circuit, their return lines were connected to the distal drainage line.

with heparin. Using a three-way connector, the access line of the PMX-HP device and CRRT were simultaneously connected to the proximal drainage line of the ECMO circuit, while their return lines were connected to the distal drainage line of the ECMO circuit (Figure 2B). At the same time that the PMX$\mathrm{HP}$ circulation began at $50 \mathrm{ml} / \mathrm{min}$ of blood flow rate, $50 \mathrm{ml}$ of fresh frozen plasma (FFP) and $50 \mathrm{ml}$ of $5 \%$ albumin were rapidly infused through the central line. Upon starting, the ECMO flow dropped and the patient's blood pressure decreased for a few seconds and then recovered. The blood flow rate was slowly increased to $100 \mathrm{ml} / \mathrm{min}$ while the patient's tolerability was observed. The session was completed in 12 hours without any other adverse events. From 4 hours after the initiation of PMX$\mathrm{HP}$, the dose of epinephrine was gradually decreased. At the end of the procedure, epinephrine could be stopped and the inotropic score dropped to 25. The $\mathrm{PaO}_{2} / \mathrm{FiO}_{2}$ ratio was increased to 267, and the ECMO was discontinued 30 hours later.

Nevertheless, CRAB was consistently detected on the blood culture throughout the patient's pediatric intensive care unit stay, and her condition deteriorated from the 18th day of life. Family counseling was carried out because the bacterial eradication had failed and additional treatment, such as the reapplication of ECMO or a second session of PMX-HP, was deemed meaningless. The patient died of multiorgan dysfunction syndrome 2 days later.

\section{DISCUSSION}

We achieved PMX-HP therapy in a neonate using an adult polymyxin B-immobilized fiber column. This cartridge (PMX20R), which contains $5 \mathrm{mg}$ of polymyxin B per gram of polystyrene fiber, is able to absorb approximately 300,000 endotoxin units in a standard hemoperfusion session [12]. The recommended duration of the hemoperfusion treatment is 2 hours at a flow rate of $80-120 \mathrm{ml} / \mathrm{min}$ repeated twice in a 24 hour period. To evaluate the effect of PMX-HP, measurement of serum cytokines such as interleukin- 6 would be helpful but not available in our laboratory. Since we could not predict its adsorption capacity in our neonate, a single session was performed for 12 hours unless adverse events occurred.

During the procedure, we were most concerned about immediate hypotension when hemoperfusion was started. Actually, we observed hypotension and decreased ECMO flow because of flow steal from the ECMO circuit, but it could be overcome by simultaneously infused additional blood products, including FFP and $5 \%$ albumin at initiation. Furthermore, for this $3.3 \mathrm{~kg}$ neonate, if the PMX-HP circuit was added, which consisted of packed RBCs and normal saline of approximately 250 $\mathrm{ml}$, a huge plasma dilution effect was expected. Before and during the procedure, FFP, platelet concentrates, and packed RBCs targeted to hemoglobin $12 \mathrm{mg} / \mathrm{dl}$ were therefore replaced.

Above all, we believe that the application of PMX-HP was technically feasible because the neonate was on ECMO. The blood flow and volume in the body's circulation could be easily controlled, including a large amount of blood transfusion, and bear the blood flow rate of PMX-HP. Also, the patient's condition could be stabilized at a steady blood temperature. Since the volume of ECMO and CRRT circuits exceeds the ne- 
onate's native blood volume, the plasma dilution effect due to the PMX-HP circuit was also deemed to be mitigated.

In our case, because the bacteria was not eradicated by antibiotics, her death was inevitable. Owing to the use of PMX-HP, she demonstrated short-lasting clinical improvement and was able to be weaned from ECMO support; however, it did not rescue the patient. Considering the nature of the PMX-HP mechanism for the removal of endotoxins, careful patient selection should be required before performing PMX-HP. In addition, some studies have reported that early initiation of PMXHP after diagnosing septic shock is associated with better clinical outcomes despite conflicting results on mortality $[13,14]$. Since the initiation of PMX-HP was delayed in our patient, the timing of its use seems to be related to the patient outcome.

We fully agree that such a high-cost therapy must have a clear prognostic effect before generalization [15]. In several studies, PMX-HP applied to patients with septic shock has shown beneficial effects on hemodynamics, pulmonary oxygenation, and mortality [1-3]. Yet, the PMX-HP in septic shock is still under debate regarding the benefits of its use. Recently, it has been noted that there is no benefit to mortality as shown in well-organized studies [15-17]. Further researches are needed to clarify the effects of PMX-HP on patient outcome.

In summary, we successfully performed hemoperfusion therapy using an adult polymyxin B-immobilized fiber column in a neonate with CRAB septic shock. Although it did not rescue the patient, there was significant short-term improvement in pulmonary oxygenation and hemodynamics, leading to wean the patient from ECMO. PMX-HP could be used as an adjunctive treatment for selected neonatal and pediatric patients with gram negative bacterial septic shock.

\section{CONFLICT OF INTEREST}

No potential conflict of interest relevant to this article was reported.

\section{ACKNOWLEDGMENTS}

This study was supported by a 2017 research grant from Pusan National University Yangsan Hospital.

\section{ORCID}

Young A Kim Hyungtae Kim Yu-Mi Kim https://orcid.org/0000-0002-8332-5200

https://orcid.org/0000-0003-3972-456X

https://orcid.org/0000-0002-3136-4566
Su Eun Park

https://orcid.org/0000-0001-5860-821X

\section{AUTHOR CONTRIBUTIONS}

Conceptualization: YAK. Data curation: YMK, SEP. Formal analysis: HK. Methodology: SEP. Project administration: YAK. Visualization: YMK. Writing - original draft: HK, YAK. Writing - review \& editing: YMK, SEP, YAK.

\section{REFERENCES}

1. Cruz DN, Perazella MA, Bellomo R, de Cal M, Polanco N, Corradi $\mathrm{V}$, et al. Effectiveness of polymyxin B-immobilized fiber column in sepsis: a systematic review. Crit Care 2007;11:R47.

2. Cruz DN, Antonelli M, Fumagalli R, Foltran F, Brienza N, Donati A, et al. Early use of polymyxin B hemoperfusion in abdominal septic shock: the EUPHAS randomized controlled trial. JAMA 2009;301:2445-52.

3. Mitaka C, Tomita M. Polymyxin B-immobilized fiber column hemoperfusion therapy for septic shock. Shock 2011;36:3328.

4. Shoji H, Tani T, Hanasawa K, Kodama M. Extracorporeal endotoxin removal by polymyxin B immobilized fiber cartridge: designing and antiendotoxin efficacy in the clinical application. Ther Apher 1998;2:3-12.

5. Machado JR, Soave DF, da Silva MV, de Menezes LB, Etchebehere RM, Monteiro ML, et al. Neonatal sepsis and inflammatory mediators. Mediators Inflamm 2014;2014:269681.

6. Hussein MH, Kato T, Sugiura T, Daoud GA, Suzuki S, Fukuda $\mathrm{S}$, et al. Effect of hemoperfusion using polymyxin B-immobilized fiber on IL-6, HMGB-1, and IFN gamma in a neonatal sepsis model. Pediatr Res 2005;58:309-14.

7. Tani T, Hanasawa K, Kodama M, Imaizumi H, Yonekawa M, Saito M, et al. Correlation between plasma endotoxin, plasma cytokines, and plasminogen activator inhibitor- 1 activities in septic patients. World J Surg 2001;25:660-8.

8. Hirakawa E, Ibara S, Tokuhisa T, Hiwatashi S, Hayashida Y, Maede Y, et al. Septic neonate rescued by polymyxinB hemoperfusion. Pediatr Int 2013;55:e70-2

9. Maede Y, Ibara S, Tokuhisa T, Ishihara C, Hirakawa E, Matsui T, et al. Polymyxin B-immobilized fiber column direct hemoperfusion and continuous hemodiafiltration in premature neonates with systemic inflammatory response syndrome. Pediatr Int 2016;58:1176-82

10. Pollack MM, Patel KM, Ruttimann UE. PRISM III: an updated pediatric risk of mortality score. Crit Care Med 1996;24:74352. 
11. Wernovsky G, Wypij D, Jonas RA, Mayer JE Jr, Hanley FL, Hickey PR, et al. Postoperative course and hemodynamic profile after the arterial switch operation in neonates and infants: a comparison of lowflow cardiopulmonary bypass and circulatory arrest. Circulation 1995;92:2226-35.

12. Tani T, Shoji H, Guadagni G, Perego A. Extracorporeal removal of endotoxin: the polymyxin B-immobilized fiber cartridge. Contrib Nephrol 2010;167:35-44.

13. Ikeda T, Ikeda K, Nagura M, Taniuchi H, Matsushita M, Kiuchi S, et al. Clinical evaluation of PMX-DHP for hypercytokinemia caused by septic multiple organ failure. Ther Apher Dial 2004;8:293-8.

14. Takeyama N, Noguchi H, Hirakawa A, Kano H, Morino K, Obata T, et al. Time to initiation of treatment with polymyxin $\mathrm{B}$ cartridge hemoperfusion in septic shock patients. Blood
Purif 2012;33:252-6.

15. Payen DM, Guilhot J, Launey Y, Lukaszewicz AC, Kaaki M, Veber B, et al. Early use of polymyxin B hemoperfusion in patients with septic shock due to peritonitis: a multicenter randomized control trial. Intensive Care Med 2015;41:975-84.

16. Iwagami M, Yasunaga H, Doi K, Horiguchi H, Fushimi K, Matsubara T, et al. Postoperative polymyxin B hemoperfusion and mortality in patients with abdominal septic shock: a propensity-matched analysis. Crit Care Med 2014;42:1187-93.

17. Fujii T, Ganeko R, Kataoka Y, Furukawa TA, Featherstone R, Doi K, et al. Polymyxin B-immobilized hemoperfusion and mortality in critically ill adult patients with sepsis/septic shock: a systematic review with meta-analysis and trial sequential analysis. Intensive Care Med 2018;44:167-78. 